\title{
Gitelman's syndrome-associated hypokalemia: A case report
}

\author{
Areen A Mitaeb and Hasan Eideh* \\ Department of Pediatrics, Palestinian Medical Complex Hospital, Palestine
}

\begin{abstract}
We report a case of male with Gitelman's syndrome who presented to pediatric emergency department mainly due to hyperemesis, fever and hypoactivity. Thus, he was admitted to the pediatric ward and intravenous potassium supplementation was commenced to counter the observed hypokalemia (2.9 mmol/L). Hyperemesis receded, and the patient's symptoms improved. However, serum potassium was still low (range 3-3.8 mmol/L). After doing further investigation by pediatric endocrinologist, the patient plasma aldosterone level was elevated (468 pg/ml) and he was found to have a homozygous missense mutation on SLC12A3 gene chr1656,921,865A > T,p.N7361 in whole Exome sequencing.
\end{abstract}

\section{Introduction}

Potassium is critical for many vital cell functions. Ninety eight percent of total body potassium is intracellular, and kidney plays a dominant role in potassium homeostasis [1]. Hypokalemia is a common clinical problem in endocrinologists and nephrologists' practice. There are many obvious causes of hypokalemia such as diarrhea, vomiting or diuretics abuse. Other causes such as tubulopathies are rarely observed and their diagnosis is more challenging [2].

Gitelman's syndrome is relatively common but overlooked cause of hypokalemia. It is an autosomal recessive inherited disease of renal tubules with a prevalence of 1-10/40,000 [3]. It is characterized by hypokalemia and hypomagnesemia caused by renal $\mathrm{K}+$ and $\mathrm{Mg} 2+$ wasting. Other typical changes are metabolic alkalosis, hypocalciuria and hyperreninemic hyperaldosteronism [4].

First symptoms of GS occur in children or young adults with normal growth are history of salt-craving behaviors, muscular cramps and weakness, constipation, nocturia, polyuria, thirst, polydipsia, cardiac arrhythmias, paresthesias [4]. Arterial hypotension is common and in many cases the most prominent symptom, however, in aging GS population hypertension can occur [5]. GS does not interfere with children's moods and social relationships and have no negative impact on their quality of life [4].

\section{Case report}

A 3 years old boy presented to the Emergency Department of Pediatrics in Ramallah Governmental hospital, Palestine, with repeated vomiting, fever and mild to moderate dehydration. His mother reported he had vomited around four times; the vomitus was not bilious consisting of normal gastric content and associated with fever which was documented by the mother (axillary temp $37.6^{\circ} \mathrm{C}$ ). On examination, patient was lethargic, moderately dehydrated, heart rate $118 / \mathrm{min}$, respiratory rate $30 / \mathrm{min}$, and blood pressure $114 / 79 \mathrm{mmHg}$ (above $95^{\text {th }}$ percentile for age and height 89-107/45-64). At the time of presentation, his weight was $13 \mathrm{~kg}$ (in $10^{\text {th }}$ percentile), height was $95 \mathrm{~cm}$ (in $25^{\text {th }}$ percentile) and head circumference was $51 \mathrm{~cm}$ (in $75^{\text {th }}$ percentile).
Laboratory tests showed that his hemoglobin was $13 \mathrm{~g} / \mathrm{dl}$; the total leukocyte count was $4.4 \times 1000$ cells per $\mathrm{mm}^{3}$ and blood and urine culture were sterile. His serum sodium was $136 \mathrm{meq} / \mathrm{l}$, potassium 2.9 $\mathrm{mmol} / \mathrm{L}$, ca $9.71 \mathrm{mg} / \mathrm{dl}$, and magnesium $1.99 \mathrm{mg} / \mathrm{dl}$ (normal 1.6-2.6 $\mathrm{mg} / \mathrm{dl}$ ) and creatinine $0.36 \mathrm{mg} / \mathrm{dl}$. Following proper treatment, his hydration status improved; but hypokalemia was persisting. Arterial blood gas analysis showed mild metabolic acidosis $\left(\mathrm{pH} 7.39, \mathrm{HCO}_{3}\right.$ 21.3, $\mathrm{PaCO}_{2}$ 34, and $\mathrm{PaO}_{2}$ 56).

On detailed history, Parents had first degree consanguineous marriage as they are cousins. Mother was 24 and father was 30 years old at marriage time and have four pregnancies, Our patient is $4^{\text {th }}$ in order of pregnancies which was conceived at age 40 . His mother had a history of behchet and asthma during gestational period for which she was taking colchicine in the first and second trimesters, prednisone $20 \mathrm{mg}$ in the first and e second trimesters which was tapered to $5 \mathrm{mg}$ in the third trimester. During pregnancy she also received potassium once due to an episode of hypokalemia, aspirin, plavix and clexane. Our patient was product of cesarean section which was done at $36+3$ week indicated due to previous cesarean section, fetal bradycardia and maternal chronic diseases. The baby was born with weight of $3000 \mathrm{~g}$, and Apgar measurements were 8 and 9 at 1 and $5 \mathrm{~min}$, respectively. He had a small (around $1 \times 2 \mathrm{~cm}$ ) hyperpigmented area over his left hand (Figure 1). He was admitted to NICU for 7 days, kept on $\mathrm{O}_{2}$ therapy due to RDS and then discharged. He had remained symptom free until the age of 5 months when the first episode of non-projectile vomiting and fever occurred.

After reviewing the past medical reports, we noticed that he experienced a long-term history of recurrent episodes of illnesses that resemble the current episode (Table 1). He was diagnosed approximately one year ago with reactive air way disease which require

${ }^{*}$ Correspondence to: Hasan Eideh, Department of Pediatrics, Palestinian Medical Complex Hospital, Ramallah, Palestine, E-mail: hasan_eideh@yahoo.com

Received: September 17, 2018; Accepted: October 03, 2018; Published: October 09,2018 
albuterol administration. Hypokalemia was pointed out in the previous three months, but we were reluctant to do further investigation considering its relation to vomiting and albuterol use. however, in the recent one month we noticed that despite the intensive replacement of potassium, its level remained constantly low (range 3-3.8 $\mathrm{mmol} / \mathrm{L}$ ) (Table 2).

The patient was referred to follow up with pediatric endocrinologist. After doing further investigation, his pediatric endocrinologist found that the aldosterone level was elevated $(468 \mathrm{pg} / \mathrm{ml})$ while the renin

Table 1. Past complains

\begin{tabular}{|c|c|c|}
\hline Age & Complains & Diagnosis/ Work up \\
\hline 11 days & RDS (congenital pneumonia) & --------------- \\
\hline 5 months & Non-projectile Vomiting + fever & ------------- \\
\hline 6 months & Constipation & $\begin{array}{l}\text { Rule out hirschsprungs (delay } \\
\text { meconium) }\end{array}$ \\
\hline 7 months & Non-projectile Vomiting + fever & --------------- \\
\hline 8 months & Non-projectile Vomiting + fever & -------------- \\
\hline 8 months & Constipation + fever & Rule out intussusceptions \\
\hline $1 \mathrm{y} \& 1 \mathrm{~m}$ & Non-projectile Vomiting 3 times & ---------------- \\
\hline 1 y \& $6 \mathrm{~m}$ & Non-projectile Vomiting + fever+ tonsillitis & ; -------------- \\
\hline 1 y \& $9 \mathrm{~m}$ & fever+ diarrhoea & Gastroenteritis \\
\hline 2 years & cough \& wheezy chest & Reactive airway on Albuterol \\
\hline $2 \mathrm{y} \& 1 \mathrm{~m}$ & Non-projectile & Vomiting + fever \\
\hline $2 \mathrm{y} \& 10 \mathrm{~m}$ & Non-projectile Vomiting + fever & Hypokalaemia \\
\hline $2 \mathrm{y} \& 11 \mathrm{~m}$ & fever + Abdominal pain + hypokalaemia & Hyperaldosteronism \\
\hline 3 years & Non-projectile Vomiting + fever & Hypokalaemia \\
\hline
\end{tabular}

Table 2. Trends in serum potassium over the patient's ten days of hospitalization

\begin{tabular}{|c|c|}
\hline Day of admission & Serum potassium \\
\hline 1 & $2.0 \mathrm{mmol} / \mathrm{L}$ \\
\hline 2 & $2.9 \mathrm{mmol} / \mathrm{L}$ \\
\hline 3 & $3.0 \mathrm{mmol} / \mathrm{L}$ \\
\hline 4 & $3.1 \mathrm{mmol} / \mathrm{L}$ \\
\hline 5 & $3.4 \mathrm{mmol} / \mathrm{L}$ \\
\hline 6 & $3.2 \mathrm{mmol} / \mathrm{L}$ \\
\hline 7 & $3.6 \mathrm{mmol} / \mathrm{L}$ \\
\hline 8 & $4.0 \mathrm{mmol} / \mathrm{L}$ \\
\hline 9 & $3.8 \mathrm{mmol} / \mathrm{L}$ \\
\hline 10 & $3.1 \mathrm{mmol} / \mathrm{L}$ \\
\hline
\end{tabular}

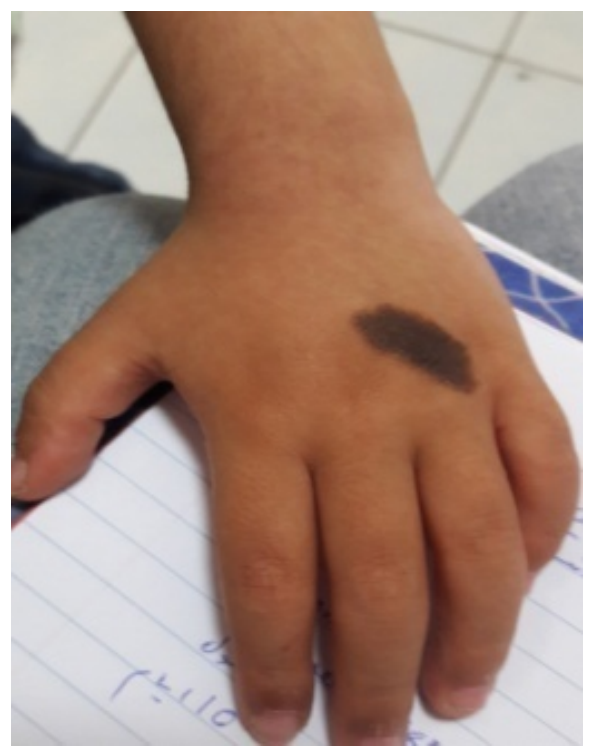

Figure 1. Hyperpigmented area over the left hand activity was normal. Renal CT was ordered to rule out an adrenal related problem but was surprisingly free. Finally, Genetic testing and whole exome sequencing was ordered while the patient was continued on $2.5 \mathrm{mg} * 2$ daily of spironolactone and $20 \mathrm{mg} * 2$ SOPA $-\mathrm{K}$ and potassium levels were followed at a regular basis.

We analyzed his genetic mutation by direct DNA sequencing. As a result, he was found to have homozygous missense mutation on SLC12A3 gene chr1656,921,865A> T,p.N7361 which encoded the thiazide-sensitive $\mathrm{NaCl}$ cotransporter. These genetic mutations are found in the majority of GS patients. We established a final diagnosis of GS based on his history and their genetic mutations.

\section{Discussion}

Gitelman's syndrome, also known as familial hypokalaemiahypomagnesaemia, is a rare primary salt-losing renal tubular disorder first reported by Gitelman in1966. It is inherited as autosomal recessive traits. The prevalence is estimated approximately at 1 in 40000 inhabitants. No gender difference is observed.

The clinical manifestations are caused by loss-of-function mutations in the solute carrier family, member 3 (SLC12A3) gene, which encodes thiazide sensitive $\mathrm{NaCl}$ co-transporter (NCCT) in the distal convoluted tubules. Normally homozygous and combined heterozygous mutations are expected in Gitelman's syndrome as it is inherited in autosomal recessive trait. The intravascular volume contraction stimulates sodium reabsorption in the collecting duct via upregulation of reninangiotensin-aldosterone system, maintaining sodium homeostasis at the expense of increased potassium and hydrogen ion secretion. This results in hypokalemia and metabolic alkalosis.

Clinical symptoms of Gitelman's syndrome include fatigue, cramps, muscle weakness, carpopedal spasms, salt craving and rarely serious symptoms such as paralysis and cardiac arrest. Growth retardation may also be seen in Gitelman's syndrome but not as frequent as in Bartter's syndrome. Most symptomatic patients present during periods of fever or when extra magnesium is lost during vomiting or diarrhea. However, many of the patients with Gitelman's syndrome remain asymptomatic during neonatal, infancy and preschool years. Often hypokalemia is only detected during routine blood taking for other reasons, as in our patient. The diagnosis of Gitelman's syndrome in this patient was made from laboratory investigation findings including hypokalemia, and hyperaldosteronism. Molecular analysis further confirmed the diagnosis.

Treatment of Gitelman's syndrome is mainly symptomatic by supplementation of potassium chloride and magnesium chloride. Observation of chondrocalcinosis. Sometimes aldosterone antagonists are required to correct and maintain serum potassium level. Patients are encouraged to maintain a high-salt diet. The long-term prognosis of Gitelman's syndrome, in terms of growth and life expectancy is favorable.

\section{Conclusion}

This case demonstrated a non-classical case of Gitelman's syndrome. He hadn't fulfilled most of the diagnostic criteria for Gitelman's syndrome including normotensive hypokalemic metabolic alkalosis, hypomagnesaemia and hypocalciuria. Once vomiting, diuretic and drug abuse are excluded from the differential diagnosis of a patient presenting with hypokalemia, rare conditions such as renal tubular acidosis, Gittelman's syndrome need to be considered which is feasible by genetic analysis. 


\section{References}

1. Giebisch G, Krapf R, Wagner C (2007) Renal and extrarenal regulation of potassium. Kidney Int 72: 397-410. [Crossref]

2. Wołyniec W (2008) Diagnosis of severe hypokalaemia in 40 years old patient with Sjogren syndrome. Forum Nefrologiczne 1: 91-95.

3. Knoers NV, Levtchenko EN (2008) Gitelman syndrome. Orphanet J Rare Dis 3: 22. [Crossref]
4. Simon DB, Nelson-Williams C, Bia MJ, Ellison D, Karet FE, et al. (1996) Molina Gitelman's variant of Bartter's syndrome, inherited hypokalaemic alkalosis, is caused by mutations in the thiazide-sensitive $\mathrm{Na}-\mathrm{Cl}$ cotransporter. Nat Genet 12: 24-30. [Crossref]

5. Caiata-Zufferey M, Zanini CA, Schulz PJ, Syrén ML, Bianchetti MG, et al. (2012) Bettinelli Living with Gitelman disease: an insight into patients' daily experiences. Nephrol Dial Transplant 27: 3196-3201. [Crossref]

Copyright: $@ 2018$ Mitaeb AA. This is an open-access article distributed under the terms of the Creative Commons Attribution License, which permits unrestricted use, distribution, and reproduction in any medium, provided the original author and source are credited. 